\title{
The Influence of Discussion Groups in a Case-Based Learning Environment
}

\author{
Anna E. Flynn \\ James D. Klein
}

The common practice of using discussion groups during case-based learning makes the role of discussion important in these learning environments. However, little empirical research has been done to investigate the influence of discussion on performance and motivation in case-based learning. The purpose of this article is to present the results of a study conducted to examine the role of discussion groups in a case-based environment. College students completed two cases either individually or in small discussion groups. Measures included two case analyses, an attitude survey, time on task, and document analysis. Results revealed significant performance and time differences between instructional methods on the first case, but not on the second case. In addition, results indicated significant differences in student attitudes between treatments. Overall, participants who worked in groups liked their method significantly better than those who worked alone, felt they learned more working in a group than they would have working alone, and expressed a preference for working in a group if they had to do the class over again. Implications for implementing case-based learning and future research are discussed.
Case-based methods are being widely implemented in a variety of learning environments. While used for many years to teach management, law, and medicine, case-based learning has become a popular method in teacher education and in instructional design and technology (Carter, 1989; Cross \& Steadman, 1996; Ertmer \& Quinn, 1999; Ertmer \& Russell, 1995; FlorioRuane \& Clark, 1990; Graf, 1991; Kinzie, Hrabe, \& Larsen, 1998; Kleinfeld, 1990, Kowalski, Weaver, \& Henson, 1990; Merseth, 1991; Shulman, 1992).

Proponents of this instructional method argue that cases make learning relevant and meaningful to the student through active participation in analyzing, discussing and solving real problems in a specific field of inquiry (Carlson \& Schodt, 1995; Doriswami \& Towl, 1963; Erskine, Leenders, \& Mauffette-Leenders, 1998; Gragg, 1954; Lawrence, 1953; Levin, 1995; Matejka \& Cosse, 1981; McNair \& Hersum, 1954; Tillman, 1995). The case method requires a teacher to be tutor, guide, coach, or facilitator, a role frequently advocated by proponents of participatory learning (Aulls, 1998; Erskine et al., 1998; Wilkerson \& Feletti, 1989). The case method also shifts the focus of learning away from memorization of facts and to the application of concepts, theories, and techniques to practical, real world problems (Albanese \& Mitchell, 1993; Carlson \& Schodt, 1995; Christensen, Garvin, \& Sweet, 1991; Erskine et al., 1998; Gallagher, Stepien, \& Rosenthal, 1992). The effective use of cases requires students to develop and use critical thinking skills and apply them to a problemsolving approach to analyze the situation and recommend realistic solutions through better 
understanding of theory (Greenwood \& Parkey, 1989; Kowalski et al., 1990; Shulman, 1992).

While several books and articles are available on writing and teaching with cases, research on the case method is limited. What exists has focused largely on comparing the case method with the lecture method. Some researchers have found that the case method produced short-term benefits for students in terms of knowledge acquisition, problem-solving abilities, and attitudes toward the topic (Cliff \& Wright, 1996; Tillman, 1995). Others reported better understanding and longer-term retention of concepts that match the needs of employers (Specht \& Sandlin, 1991). Other research illustrated the practical application of theories and concepts as tools for problem solving (Carlson \& Schodt, 1995).

Results have been mixed when exam performance is measured. Improved scores were reported in a study of a case-based human anatomy and physiology course (Cliff \& Wright, 1996). Higher grades were reported for students in a problem-based learning group in pharmaceutical clerkship rotations than for those students in a didactic lecture group (Nii \& Chin, 1996). However in a study of three case-based economics courses, students in the lecture method did better on a 20-point theory test than did students in the case method course (Stolovich \& Yapi, 1997).

The common practice of using discussion groups in case classes makes the role of discussion important in a case-based learning environment. Proponents of the case method argue that discussion is key to the case process (Christensen, 1987; Erskine et al., 1998; Haynes \& Helms, 1993; Levin, 1995; Merseth, 1991; Richardson, 1991; Tillman, 1995; Welty, 1989). According to Erskine, Leenders, and MauffetteLeenders (1981), many case teachers believe that small group discussions form a vital part of the student preparation task. These views are based on the assumption that a group may cover a variety of points faster than the individual, thus cutting down on total preparation time, and that collective effort will surpass individual preparation.

Little empirical research has been done to investigate the influence of discussion on perfor- mance and motivation in case-based learning. Authors who support the use of discussion (or a particular approach to facilitating discussion) in a case-based course rely largely on anecdotal evidence (Erskine et al., 1998; Herreid, 1994; Knechel, 1992; Siciliano \& McAleer, 1997; Tillman, 1995).

Some empirical studies have addressed the question of whether or not different approaches to discussion influenced outcomes. Droge and Spreng (1996) compared instructor-led and student-led case analysis methods and found that students perceived that the student-led case class was superior in terms of career preparation, use of time, involvement and satisfaction, and achieving educational goals (such as understanding the material) and specific skill competencies (such as oral skills). Levin (1995) compared what experienced and inexperienced teachers learned from reading and writing about a case to what they learned when discussing the case. She found that discussion appeared to act as a catalyst for reflection for very experienced teachers. For less experienced teachers and student teachers, discussion appeared to allow them to clarify or elaborate their understanding and increase their perspective on the issues in the case. Teachers in the control group (only reading and writing about a case) reiterated their original thinking about the case, rather than gaining new perspectives. Levin also found that there was little transfer to a similar case one month later.

In a qualitative study of case discussions, Griffith and Laframboise (1997) analyzed audiotapes of small- and large-group case discussions. They were interested in how course content was applied to the discussion of cases and the different consultative patterns of the students as they identified and reflected on the issues in the cases. They found that discussions were based more on personal experiences than on theory and course content. Also, more meaning was constructed during small group discussions during which the group reached consensus rather than in large group discussions.

While research on the use of discussion groups in case methods is limited, research on the use of small groups in college classrooms has consistently reported improved involvement 
and gains in achievement (Cooper \& Mueck, 1992; Cooper, Robinson, \& McKinney, 1994; Johnson, Maruyama, Johnson, Nelson, \& Skon, 1981; Slavin, 1983). In What Matters Most in College: A Critical Four Years Revisited, Astin (1992) reported on results from research on 200 colleges, which suggested that student-student interaction is a key predictor of cognitive and attitudinal changes in college. When done effectively, small group learning fosters student-student interaction.

Small groups can be used within the context of a number of instructional methods, including cooperative learning, collaborative learning, problem-based learning, or case-based learning. Small groups are used in all of these to enhance learning and performance. While proponents of each of these methods believe that student to student interaction will lead to better performance, they disagree on the way in which small groups are structured, the tasks performed in small groups, and when small groups should be used.

Cooperative and collaborative learning research describes groups along a continuum from loosely structured to highly structured, interdependent groups. The effect of group structure on achievement has been the subject of a number of articles (Cavalier, Klein, \& Cavalier, 1995; Horn, Collier, Oxford, Bond, \& Dansereau, 1998; Johnson \& Johnson, 1989; King, Staffieri, \& Adelgais, 1998; Klein \& Doran; 1999). Cooperative learning focuses on highly structured groups and emphasizes individual and group accountability. Collaborative learning uses less structured groups and grades may be based on individual performance. Bruffee (1995) summed up the similarities and differences between cooperative and collaborative learning and concluded that both encourage learning through sharing ideas. However, in cooperative learning, accountability is ensured by leaving authority with the teacher while in collaborative learning some accountability is lost because authority is left with the students. In a collaborative-learning classroom, student roles and tasks are less structured by the teacher and governed mostly by the students themselves (Bruffee, 1995).

Problem-based learning takes a different approach to the role of small groups. The prob- lem is the focal point for the group. Each small group must identify what they know already and what they need to know, and then proceed to gather the missing relevant information and resolve the problem. Problem-based learning research addresses the role of the group in achievement and motivation, the effect of a tutored or tutorless group, and breadth versus depth of content acquisition (Gallagher \& Stepien, 1996; Gallagher et al., 1992; White, 1996).

The purpose of the current study was to investigate the role of small discussion groups in case-based learning. For the purposes of this study, the term small discussion group learning was defined as collaborative groups of four or five students working together toward a common learning goal. While there are many ways to teach with cases, the case method used in the current study treated small groups as selfdirected collaborative teams. The instructor acted as a facilitator for the class, but did not interact with each group. Similar to the problembased learning approach, students started with a case, determined what concepts and theories were relevant, and decided how to apply them to resolve a case problem.

The major question addressed by this study was: What is the effect of small discussion groups on performance, student attitudes, and time on task in a case based learning environment? The study also addressed whether individual students work through cases differently than those who work in small discussion groups.

\section{METHOD}

\section{Participants and Design}

The participants were 94 juniors and seniors majoring in supply chain management at a large university located in the southwestern United States. They were enrolled in one of two sections of introductory purchasing and supply management, a required course for their major. One class section consisted of 47 students ( 26 males and 21 females); the other, 47 students ( 32 males and 15 females).

This study used a posttest-only control group 
design. The independent variable was instructional method (discussion group versus individual). The dependent variables were performance on two cases, student attitudes, time on task, and number of changes to the case analyses. Since it was not possible to randomly assign each student to a treatment condition, one class section was selected randomly as the discussion group treatment and the other as the individual treatment. Participants in the discussion group treatment were assigned randomly to small groups of four or five students. A $t$ test comparing overall grade point averages (GPAs) of participants indicated that there was no statistically significant difference in ability between students enrolled in the two course sections.

\section{Procedures}

The study was conducted as part of the course during seven 75 -min class periods. The same instructor taught both class sections and blindscored all cases against a previously tested scoring rubric. The method and materials used in this study were first tested in a pilot study and improved prior to this research.

All participants were taught a case analysis process and then completed two case analyses. Participants in both treatments spent $35 \mathrm{~min}$ of class time reading and preparing each case individually. Participants in the individual treatment continued working alone for the remaining $35 \mathrm{~min}$ of class time to complete the case analysis. Participants in the discussion group treatment worked in a group of four or five students for the remaining $35 \mathrm{~min}$ to complete the analysis.

In the weeks leading up to the study, participants were taught the basic concepts, tools, and techniques for administering the purchasing and supply management function in a company. The material was presented primarily in an interactive lecture format. The content and format of the lectures were the same for both class sections. During the study, participants had to decide which concepts and theories were relevant and apply them to resolving the case problems.

The following sections explain the step-bystep procedures of the study.
Orientation to the case method. Two 75-min class periods were devoted to orienting students in both treatments to the case method. During the orientation, all participants were taught a structured problem-solving process described by Mauffette-Leenders, Erskine, and Leenders (1997), and then practiced this method on a sample case. This process requires students to complete 10 steps while analyzing a case:

1. Identify the problem

2. Determine the nature of the problem or the learning issues in the case

3. Decide the importance and urgency of the situation

4. Analyze the situation quantitatively and qualitatively

5. Generate alternatives

6. Establish decision criteria

7. Select the preferred alternative and predict the outcome

8. Outline an action and implementation plan

9. Identify relevant missing information, and

10. List the assumptions made during analysis.

The orientation consisted of several steps. First, participants were told to read Chapter 3, "Individual Preparation," in the text, Learning with Cases (Mauffette-Leenders et al., 1997), before coming to class. During class, the instructor explained the steps in the case-analysis process and walked the class through an analysis of a short case. Students received oral feedback during the instructor-led discussion of the case and were given 10 bonus points for turning in a case preparation chart for the orientation case.

Participants in the discussion group treatment were also told to read Chapter 4, "Small Group Discussion," in the Learning with Cases text (Mauffette-Leenders et al., 1997). The instructor discussed the role of small discussion groups in the case-analysis process as described in the text. These participants were advised that the purpose of the discussion group was to supplement, not replace, individual preparation. The following guidelines were given to the students for the small group discussion:

- Each individual must attend the small group discussion fully prepared. 
- Each member of the group must participate actively in the discussion.

- It is not necessary to have a group leader, a group recording secretary, or group spokesperson.

- It is not necessary to achieve consensus or a "group position."

- Establish and stick to a time limit.

Experiment-case analysis. During the two weeks following the orientation, all participants prepared two written case analyses during class time using the structured case-analysis process taught in the orientation session. Participants in both treatments spent the first $35 \mathrm{~min}$ of each class analyzing the case alone and writing their analysis in black ink on a case preparation chart. The procedure varied by treatment after $35 \mathrm{~min}$ of individual preparation. Participants in the individual treatment continued working alone for the next $35 \mathrm{~min}$ of each class, while those in the discussion group treatment worked in a small group to complete the case preparation chart. Participants in both conditions made additions or changes to their case preparation charts in red ink. All participants were told that they had the additional $35 \mathrm{~min}$ to complete the case analysis, but they could leave at any point when they thought they had completed a thorough case analysis. At the end of each case class, all students turned in a completed case preparation chart as they left class; the stop time for each participant was noted on the chart. The instructor led a class discussion of each of the cases in the class period following the individual and group treatment. Students received a maximum of 40 points for each case analysis; written feedback was provided on the graded cases. In the class period after the second case discussion, students in both treatments were asked to complete an attitude survey administered by someone other than the instructor.

\section{Materials}

The materials used in this study included readings from two textbooks, three problem-based cases, a case preparation chart, a scoring rubric, and an attitude survey.
Text 1. Purchasing and Supply Management (Leenders, Fearon, \& Flynn, 1997) is a standard textbook with chapters on each topical area. There are several cases at the end of each chapter. This text was used as the basis of the course for content acquisition prior to the implementation of the cases. The cases in the book correspond to the content of each chapter. Participants were allowed to use this text as a reference during the research study.

Text 2. Learning with Cases (Mauffette-Leenders et al., 1997) was written specifically for students in a case class. It provides practical advice, suggestions and reminders to maximize learning with cases. The text includes the 10-step process for analyzing cases discussed above and provides a detailed description of each step. Participants were allowed to use this text as reference material during the study.

Cases. This study included three problem-based cases from the Purchasing and Supply Management text (Leenders et al., 1997)—(a) the Kramer Case (for orientation), (b) the Dryden Inks Case, and (c) the Earl's Candies Case. For the purposes of this study, a case was defined as "a description of an actual situation, commonly involving a decision, challenge, an opportunity, a problem, or an issue faced by a person (or persons) in an organization" (Mauffette-Leenders et al., 1997, p. 2).

The cases used in this study were chosen because of their fit with the content taught earlier in the semester and because of their place on the case difficulty described by MauffetteLeenders et al. (1997). The difficulty of a case can be viewed on three dimensions-analysis, concept, and presentation. The cases chosen for this study generally fell into a 2-1-1 category. This means that the immediate issue or problem was stated, and the cases dealt with one or two simple concepts. The task of participants was to analyze the situation, generate and evaluate options against decision criteria they designated, make a decision, and develop an action and implementation plan.

Case preparation chart. A case preparation chart was developed by the researcher to provide participants with a form to write out their analysis 
of each case. The chart was broken into three parts: (a) problem definition, (b) analysis and alternatives, and (c) evaluation and recommendation. Each part included several subsections that required students to answer specific questions or identify pertinent information for a specific step of the problem-solving process. Each part is described in detail below.

Part I: Problem definition. The problem definition section of the case preparation chart required students to identify the (a) immediate issue - the specific decision, problem, challenge, or opportunity faced by the decision maker stated in the case; (b) basic issues-the concepts, topics, and broader issues of concern related to the case; (c) importance-the impact of the immediate issue on the whole organization, not the decision maker or the department; and (d) urgency - the time frame stated or suggested by the case data for resolving the immediate issue.

Part II: Analysis and alternatives. The second part of the case preparation chart required students to interpret information provided in the case and generate a list of possible solutions. This included (a) quantitative analysis-performing financial or other numerical analysis using data available in the case; (b) qualitative analysis-interpreting all non-numerical case data; (c) missing information-identifying missing information that is relevant to the problem and where and how the information might be obtained; (d) assumptions-identifying assumptions made when doing analysis; and (e) generating alternatives-listing different ways to resolve the immediate issue.

Part III: Evaluation criteria and recommendation. The last part of the case preparation chart required students to (a) establish decision criteria to compare the pros and cons of each alternative before selecting a course of action; (b) recommend a preferred alternative and predict an outcome; and (c) develop an action plan that addressed the key steps in implementing the decision. The action plan required students to answer these five questions: (a) Who must act? (b) What must they do? (c) When must they do it? (d) Where must it happen? (e) How should it be done?

Scoring rubrics. In order to assess student per- formance on the cases, a scoring rubric was developed by the researchers. The rubric for this study was developed and tested in a pilot study conducted prior to this research project and refined based on the pilot.

The scoring rubric used a rating scale that allowed the rater to choose from among different descriptions of actual performance to assign scores. Overall performance on the cases was measured according to the degree of quality of an answer, not the presence or absence of a correct answer or case solution. The basic design of the rubric paralleled the case analysis process itself. The case preparation chart had three major categories: (a) problem definition, (b) analysis and alternatives, and (c) evaluation and recommendation. The scoring rubric was used to assess the degree to which a student successfully performed the case analysis at each stage of the problem-solving process. Each case was worth a maximum total of 40 points. Problem definition was worth 12 points, alternatives and analysis was worth 20 points, and evaluation criteria and recommendation was worth 8 points. The descriptions for levels of performance for each of the items were drawn primarily from the "Case Teaching Notes" included in the Instructor's Manual accompanying the textbook, Purchasing and Supply Management (Leenders et al., 1997).

The case preparation chart for each participant was identified by an identification number to ensure blind grading. Furthermore, cases from the two class sections were mixed together to ensure that the rater did not know which class the case came from. The rater scored a case by reading the case preparation chart against the scoring rubric

Attitude survey. An 11-item survey was developed by the researcher to measure student attitudes toward the treatments implemented in the study. Respondents used a four-point Likert scale ( $1=$ strongly agree, $4=$ strongly disagree $)$ on items 1-10 to rate their attitude toward working in a group or alone, their perception of the impact the treatment had on their performance, and their views on the case process itself. Item 11 was an open-ended question that asked "During the case preparation process, did you change 
any of your thinking about the cases? If yes, what?" Someone other than the instructor administered the attitude survey during the next class period after the second case was discussed.

\section{Data Analysis}

Multiple analysis of variance (MANOVA) was conducted on the performance data from Case 1 and Case 2 to compare scores between the treatment groups. The dependent measures for the MANOVA were total score on the case and scores on each of the three sections of the case preparation chart. A follow-up one-way analysis of variance (ANOVA) was conducted on the scores from each section of a case if a significant MANOVA result was found. MANOVA was also conducted on data from the attitude survey. ANOVA was then conducted on each item on the survey if a significant MANOVA result was found. ANOVA was also conducted on the timeon-task data. The number of times each participant added, changed or deleted a comment on section 1,2, or 3 of the case preparation chart during treatment was counted. Separate chisquare analyses were conducted on frequency data for each section (problem identification, analysis and alternatives, and evaluation and recommendation).

\section{RESULTS}

The results are reported below for performance on Cases 1 and 2, time spent on each case, student attitudes, and document analysis.

\section{Performance}

Case 1. Table 1 shows the mean scores and standard deviations for performance on the three main sections of Case 1 and the total score. These data show that the average total for Case 1 was $23.13(58 \%)$ for students who worked in groups and $22.39(56 \%)$ for students who worked alone. The range of scores was from 11 to 33 for those who worked in groups and 7 to 34 for those who worked alone. A MANOVA conducted on scores for Case 1 indicated that instructional method had a significant effect on performance, $F(4,87)=4.713, p<.05$. Follow-up univariate analyses indicated that students who worked in groups $(M=12.00)$ performed significantly better than those who worked alone $(M=10.33)$ on the analysis and alternatives section of Case 1, F $(1,92)=6.79, p=.011$. Furthermore, students who worked alone $(M=4.30)$ performed significantly better than those who worked in groups $(M=3.46)$ on the evaluation and recommendation section, $F(1,92)=5.742, p<.05$. However, follow-up analyses did not show a significant effect for instructional method on the problem

\section{Table $1 \square$ Mean Scores and Standard Deviations for Performance on Case 1}

\begin{tabular}{lcc}
\hline Test Section Score & Individual & Group \\
\hline Problem definition & 7.43 & 7.63 \\
& $(2.23)$ & $(2.89)$ \\
Analysis and alternatives & 10.33 & 12.00 \\
& $(3.59)$ & $(2.47)$ \\
Evaluation and & 4.30 & 3.46 \\
recommendation & $(1.99)$ & $(1.35)$ \\
Total score & 22.39 & 23.13 \\
& $(5.52)$ & $(4.91)$
\end{tabular}

Note: Maximum possible scores were 12 on problem definition, 20 on analysis and alternatives, 8 on evaluation and recommendation, and 40 on total score.

definition section of the case or on total score.

Case 2. Table 2 shows the mean scores and standard deviations for performance on the three main sections of Case 2 and the total score. These data show that the average total for Case 2 was $23.66(59 \%)$ for students who worked in groups and $22.89(57 \%)$ for students who worked alone. The range of scores was from 11 to 33 for those who worked in groups and 14 to 34 for those who worked alone. A MANOVA conducted on performance data for Case 2 indicated that instructional method did not significantly affect performance, $F(4,87)=1.551, p>.05$.

\section{Time on Task}

Participants in both treatments had a total of 75 min to complete each case. Time data revealed 
Table $2 \square$ Mean Scores and Standard Deviations for Performance on Case 2

\begin{tabular}{lcc}
\hline Test Section Score & Individual & Group \\
\hline Problem definition & 7.74 & 8.70 \\
& $(2.44)$ & $(2.44)$ \\
Analysis and alternatives & 10.28 & 10.19 \\
& $(2.84)$ & $(2.46)$ \\
Evaluation and & 4.87 & 4.77 \\
recommendation & $(2.10)$ & $(1.71)$ \\
Total score & 22.89 & 23.66 \\
& $(5.06)$ & $(5.10)$
\end{tabular}

Note: Maximum possible scores were 12 on problem definition, 20 on analysis and alternatives, 8 on evaluation and recommendation, and 40 on total score.

that the average number of minutes spent on Case 1 was 70.48 for students who worked alone and 74.93 for those who worked in groups. The range was from 44 to $78 \mathrm{~min}$ for those who worked individually and from 72 to $75 \mathrm{~min}$ for those who worked in groups. ANOVA indicated that students who worked in groups spent significantly more time on Case 1 than those who worked individually, $F(1,92)=20.887, p<.001$.

The average number of minutes spent on Case 2 was 69.26 for those who worked alone and 68.68 for those who worked in groups. The range was from 47 to $75 \mathrm{~min}$ for those who worked alone and from 67 to $78 \mathrm{~min}$ for those who worked in groups. ANOVA indicated there was no significant difference between treatments for the amount of time spent on Case 2.

\section{Student Attitudes}

The means and standard deviations for student responses on each of the attitude items are reported in Table 3. A MANOVA indicated that the instructional method had a significant effect on student attitudes, $F(10,81)=6.860, p<.01$. Follow-up univariate analysis indicated that students who worked in groups (a) liked their instructional method better than those who worked alone, $F(1,81)=16.329, p<.001$; (b) felt that they learned more from their instructional method than those who worked alone, $F(1,80)=$ $33.188, p<.001$; and (c) reported that they would prefer to work in a group if they had to do the class over again. Those who worked alone reported (a) less preference for working alone if they had to do the class over again, $F(1,80)=$ $17.048, p<.001$; (b) that they generally prefer to work in a group when solving problems; and were (c) less likely to report a general preference for working alone, $F(1,78)=18.887, p<.001$. However, students who worked alone were significantly more satisfied that they had enough time to complete the cases, $F(1,80)=11.259, p<$ .001 ; and were more likely to report that they used supplemental materials (the book, notes) to complete the case preparation chart than those who worked in groups, $F(1,81)=4.966, p=.05$.

The attitude survey also included one openended question: "During the case preparation process, did you change any of your thinking about the cases? If yes, what?" These data show that 23 students who worked in groups and 17 who worked alone reported changing their thinking during the case preparation process. Of those in groups who reported changing their thinking, 12 of the comments were related to getting other points of view and new ideas for the case analysis. Furthermore, 4 people reported changing some aspect of the analysis section, 3 changed the problem definition, 3 changed their decision criteria and recommendation, and 1 reported changing almost everything. A typical comment was, "I often encountered points of view I had not thought of on my own."

Of those who worked alone who reported changing their thinking during the case preparation process, four changed the problem definition, two changed their analysis, and one changed the decision criteria and recommendation. Five students reported changes such as coming up with new ideas, more detail, and better understanding of the logic of the analysis as they worked. A typical comment was, "I would think the problem out as time went on. The more I wrote and thought about the problem, the more ideas I had."

\section{Document Analysis}

Participants in both treatments wrote in black ink while they worked alone for the first $35 \mathrm{~min}$ 
Table $3 \square$ Means and Standard Deviations for Responses to Attitude Survey

\begin{tabular}{|c|c|c|c|}
\hline Attitude Statements & Individual & Group & Total \\
\hline $\begin{array}{l}\text { 1. I liked working by myself on the cases / } \\
\text { discussing the cases in a small group.* }\end{array}$ & $\begin{array}{r}2.33 \\
.84\end{array}$ & $\begin{array}{r}1.65 \\
.58\end{array}$ & $\begin{array}{r}2.00 \\
.80\end{array}$ \\
\hline $\begin{array}{l}\text { 2. I/my group used supplemental materials (the } \\
\text { book notes) to complete the case preparation } \\
\text { chart.* }\end{array}$ & $\begin{array}{r}1.80 \\
.91\end{array}$ & $\begin{array}{r}2.15 \\
.77\end{array}$ & $\begin{array}{r}2.01 \\
.85\end{array}$ \\
\hline $\begin{array}{l}\text { 3. Using cases was a good way to learn this } \\
\text { material. }\end{array}$ & $\begin{array}{r}2.02 \\
.71\end{array}$ & $\begin{array}{r}1.97 \\
.53\end{array}$ & $\begin{array}{r}2.00 \\
.62\end{array}$ \\
\hline $\begin{array}{l}\text { 4. I learned more working by myself/in a group } \\
\text { than I would have learned working in a group } \\
\text { or alone. }\end{array}$ & $\begin{array}{r}2.86 \\
.65\end{array}$ & $\begin{array}{r}1.88 \\
.79\end{array}$ & $\begin{array}{r}2.38 \\
.87\end{array}$ \\
\hline $\begin{array}{l}\text { 5. I/my group was able to use the class period } \\
\text { productively while working on the cases. }\end{array}$ & $\begin{array}{r}2.17 \\
.76\end{array}$ & $\begin{array}{r}2.00 \\
.68\end{array}$ & $\begin{array}{r}2.09 \\
.72\end{array}$ \\
\hline $\begin{array}{l}\text { 6. I/my group had enough class time to } \\
\text { complete the case preparation chart. }{ }^{* *}\end{array}$ & $\begin{array}{r}2.58 \\
.82\end{array}$ & $\begin{array}{r}3.21 \\
.80\end{array}$ & $\begin{array}{r}2.88 \\
.87\end{array}$ \\
\hline $\begin{array}{l}\text { 7. Analyzing and discussing two cases provided a } \\
\text { conceptual foundation that will prepare me to } \\
\text { solve similar problems in a real job. }\end{array}$ & $\begin{array}{r}2.09 \\
.61\end{array}$ & $\begin{array}{r}2.10 \\
.63\end{array}$ & $\begin{array}{r}2.10 \\
.62\end{array}$ \\
\hline $\begin{array}{l}\text { 8. If I had to do this class over again, I would } \\
\text { prefer to work alone/in a group on the cases.* }\end{array}$ & $\begin{array}{r}2.51 \\
.81\end{array}$ & $\begin{array}{r}1.85 \\
.66\end{array}$ & $\begin{array}{r}2.19 \\
.81\end{array}$ \\
\hline $\begin{array}{l}\text { 9. Generally, I prefer to work alone/in a group } \\
\text { when solving problems.** }\end{array}$ & $\begin{array}{r}2.52 \\
.78\end{array}$ & $\begin{array}{r}1.87 \\
.57\end{array}$ & $\begin{array}{r}2.20 \\
.76\end{array}$ \\
\hline $\begin{array}{l}\text { 10. I learned more from the cases than I } \\
\text { would have from a lecture focusing on } \\
\text { the same issues or problems. }\end{array}$ & $\begin{array}{r}2.36 \\
.76\end{array}$ & $\begin{array}{r}2.16 \\
.55\end{array}$ & $\begin{array}{r}2.26 \\
.67\end{array}$ \\
\hline
\end{tabular}

Note: Responses were on a scale of 1 to 4 where $1=$ strongly agree, $2=$ agree, $3=$ disagree, and $4=$ strongly disagree. ${ }^{*} p<.05 .{ }^{* *} p<.01$.

and in red ink for the remaining 35 min (working alone in the individual treatment or working with others in the group treatment). Document analysis consisted of a count of the number of comments written in red which indicated an addition, deletion, or change to one of the three main sections of Case 1 and Case 2.

Table 4 shows the number of changes made to each section of Cases 1 and 2 and the total number of changes made to each case. Chisquare analyses revealed that participants in groups made significantly more changes to Case $1\left(\chi^{2}=26.78, p<.05\right)$ and to Case $2\left(\chi^{2}=25.46, p\right.$ $<.05)$ than those who worked alone. Students who worked in groups also made significantly more changes to the problem definition section of Case $1\left(\chi^{2}=106.00, p<.05\right)$ and Case $2,\left(\chi^{2}=\right.$ $116.65, p<.05)$ than those who worked alone. Participants in both treatments made the most changes to the analysis and alternatives section of the preparation chart for Cases 1 and 2.
Table $4 \square$ Frequencies for Number of Additions, Deletions or Changes to Cases 1 and 2

\begin{tabular}{lrc} 
& Individual & Group \\
\hline Case 1 & & \\
$\begin{array}{lr}\text { Problem definition } \\
\text { Analysis and alternatives }\end{array}$ & 605 & 204 \\
$\begin{array}{l}\text { Evaluation and } \\
\text { recommendation }\end{array}$ & 386 & 671 \\
Total & 1033 & 407 \\
$\begin{array}{lr}\text { Case 2 } \\
\text { Problem definition }\end{array}$ & 28 & \\
$\begin{array}{l}\text { Analysis and alternatives } \\
\text { Evaluation and }\end{array}$ & 597 & 186 \\
recommendation & 382 & 545 \\
Total & & 404 \\
& 907 & 1135 \\
\hline
\end{tabular}

Table 5 shows the number of participants who prepared each section of the case preparation chart during the first $35 \mathrm{~min}$ of each class period. On both cases, most of those who 
Table $5 \square$ Number of participants who prepared each section in the first half of the class period.

\begin{tabular}{|c|c|c|c|c|}
\hline & \multicolumn{2}{|c|}{ Case 1} & \multicolumn{2}{|c|}{ Case 2} \\
\hline & $\begin{array}{l}\text { Alone } \\
n=47\end{array}$ & $\begin{array}{l}\text { Group } \\
n=46\end{array}$ & $\begin{array}{c}\text { Alone } \\
n=46\end{array}$ & $\begin{array}{l}\text { Group } \\
n=47\end{array}$ \\
\hline \multicolumn{5}{|l|}{ Part 1: Problem definition } \\
\hline $\begin{array}{l}\text { a. Immediate issue } \\
\text { b. Basic issue }\end{array}$ & $\begin{array}{l}47 \\
46\end{array}$ & $\begin{array}{l}46 \\
46\end{array}$ & $\begin{array}{l}45 \\
45\end{array}$ & $\begin{array}{l}47 \\
47\end{array}$ \\
\hline c. Importance & 47 & 45 & 45 & 45 \\
\hline d. Urgency & 45 & 45 & 44 & 45 \\
\hline \multicolumn{5}{|l|}{ Part 2: Analysis and alternatives } \\
\hline b. Missing information & 14 & 38 & 18 & 43 \\
\hline c. Assumptions & 11 & 34 & 13 & 42 \\
\hline d. Alternatives & 9 & 31 & 10 & 43 \\
\hline \multicolumn{3}{|l|}{ Part 3: Evaluation and recommendation } & 3 & 32 \\
\hline b. Action plan & 2 & 3 & 0 & 9 \\
\hline
\end{tabular}

worked alone completed only the problem identification section and the first subsection of the analysis and alternatives section during the first 35 min of class. Very few students in the individual treatment worked on the evaluation and recommendation section during the first half of either class period. In contrast, most students who worked in groups completed both the problem identification and the analysis and alternatives sections during the first half of the class. This suggests that most students who worked in groups had done some level of individual preparation for Part 1 and Part 2 prior to the small group discussion. Furthermore, participants who worked in groups changed their behavior from Case 1 to Case 2. Of 46 students in the group treatment, 17 did some work on the evaluation and recommendation section prior to discussing Case 1 with their groups, while this number increased to 32 out of 47 on Case 2.

\section{DISCUSSION}

The purpose of this study was to investigate the role of small discussion groups in a case-based learning environment. College students completed two cases in a controlled environment in which the only difference was whether they worked alone or in small groups during half of two class periods. Measures included two case analyses, an attitude survey, time on task, and document analysis.
Results indicated that instructional method influenced performance on Case 1. Students who worked in groups performed significantly better than those who worked alone on the analysis and alternatives section of Case 1. However, students who worked alone performed significantly better than those who worked in groups on the evaluation and recommendation section of the case.

These results might be explained by examining how students in the small group treatments completed the case preparation chart. Document analyses revealed that a majority of students who worked in groups completed most of the work on the analysis and alternatives section prior to discussing the case with their group. However, only a few of these students (37\%) worked on the evaluation and recommendation section of the case before moving to the small group discussion. This suggests that students in the small group treatment were prepared to discuss the analysis and alternatives section of the case but not the evaluation and recommendation section.

While very few research studies have been conducted to examine the use of small groups in the case environment, advocates of case-based learning suggest that group discussion is key to the case process (Christensen, 1987; Erskine et al., 1998; Haynes \& Helms, 1993; Levin, 1995; Merseth, 1991; Richardson, 1991; Tillman, 1995; Welty, 1989). Others have indicated that individ- 
ual preparation is the basis for subsequent work on cases and the foundation of learning from cases (Mauffette-Leenders et al., 1997; Brookfield \& Preskill, 1999). Results of the current study suggest that small group discussion enhances student performance on cases only when discussion is combined with individual preparation.

It is quite possible that the task of analyzing the case and generating alternatives was better suited to group discussion than the task of evaluation and recommendation. According to Slavin (1989), the tasks of analyzing, explaining, and synthesizing should be enhanced by small group effort. Furthermore, Wilkinson and Dubrow (1991) theorized that discussion can be used to help students interpret content and analyze information since it is difficult for students to learn how to do analysis.

In the evaluation and recommendation section, students compared the alternatives generated in the analysis and alternatives section to a set of decision criteria and recommended one alternative to implement. Then they outlined the key steps in an action and implementation plan. Most of the analytical work may have been done in the previous section, analysis and alternatives, making the task of selecting and recommending an alternative suited to individual effort.

It is also likely that results for performance were due to the amount of time available for completing Case 1 and how students allocated their time to complete it. Because this study was implemented in an actual course, all students had $75 \mathrm{~min}$ to complete the case. Results for time on task revealed that students in the small groups spent significantly more time on Case 1 than students who worked alone. Students who worked alone spent an average of $5 \mathrm{~min}$ less on the case than did those who worked in small groups. Time data show that students who worked in groups used the entire class time to complete the case, with little variation between those students. The range of time was from 44 to $78 \mathrm{~min}$ for those who worked alone and from 72 to $75 \mathrm{~min}$ for those who worked in groups.

Working with others may simply take more time than working alone on a problem. Slavin (1990) reported that "most studies that have measured time on task have found a higher proportion of engaged time for cooperative learning students than for control students" (p. 47). However, all students in the current study were instructed to turn in their individual case preparation chart when they believed they had done a thorough job. Therefore, each student had the choice of leaving the group discussion or remaining for the full class period. Students in every discussion group turned in their charts at the same time.

However, students who worked in groups may not have allocated their time wisely. Document analysis revealed that these students spent time making unnecessary changes to the problem definition section of the case and little time on the evaluation and recommendation section. Furthermore, results for attitude suggested that students in the small groups did not have enough time to complete the case preparation chart.

Allocation of time appears to be different for students who worked alone. Document analysis revealed that most of these students completed the problem definition section of the case during the first $35 \mathrm{~min}$ of the class and made few additions to it during the remainder of the class. Few individuals completed the analysis and alternatives section of the case during the first $35 \mathrm{~min}$. It appears that individuals were more likely than small groups to work though the case in a linear fashion, section by section. This suggests that students who worked alone spent a larger proportion of their time on the evaluation and recommendation section of the case.

While results revealed significant performance differences between treatments on Case 1 , there were no significant differences on Case 2. Document analysis indicated that students in the small groups allocated more time to work on the evaluation and recommendation section of Case 2 before they discussed the case. Furthermore, students in the small groups made fewer changes to the problem definition and analysis and alternatives sections of Case 2 than they did on Case 1. This indicates that more students who worked in groups came to the group discussion prepared to discuss the evaluation and recommendation section. This additional preparation may have enhanced performance for small 
group students slightly since they did as well on section 3 as those who worked alone.

It is likely that the feedback provided to students after Case 1 influenced how students approached Case 2 . Since the case analysis process was new to all students, the level of understanding of the process may have varied among students even after the class discussion of the orientation case. After completing Case 1, both classes received verbal feedback from the instructor, who led a 75-min discussion of Case 1. Consequently, on Case 2 students in both classes may have had a similar level of understanding of the case-analysis process and then performed about the same.

However, overall performance scores on both cases were quite low. It is quite typical of students using the case-analysis process for the first time to require a number of cases before gaining a good grasp of the process. Also, the scoring rubric was designed to reflect an ideal case analysis. For actual grading purposes in a typical classroom environment, the instructor would adjust the scores based on an assessment of the performance of all class members in comparison to one another. Since these data were collected for research purposes, no adjustment to scores was made.

Another possible explanation for the low scores is that the students may have needed more time than was available in a standard class period to do a thorough case analysis. The fact that students who worked in groups changed their behavior from Case 1 to Case 2 suggests that students learn from the group process and adjust their efforts and time allocation in ways that they perceive will lead to enhanced performance.

It is especially interesting that on both cases those who worked in groups appear to have spent time on section 1 , problem definition, even though they probably didn't need to. The cases were selected based on their low level of analytical, conceptual, and presentation difficulty. The instructor told students that the problem statement was given explicitly in the case. However, document analysis revealed that many of those who worked in groups added comments to this section. This may indicate uncertainty with a new process, and the need for reassurance from the group that the individual was, indeed, on the right track. Instructor observation of the group discussions revealed that students were spending an inordinate amount of time on this aspect of the case analysis despite being told that the case problem was explicitly stated in the case. Many students reported that they did not feel they had enough time for the case analysis, yet they chose to spend time unwisely on a part of the analysis that did not actually require or deserve the time allocation.

In addition to results for performance, results indicated a significant difference in student attitudes between instructional methods. Overall, those who worked in groups liked the method significantly better than those who worked alone, felt they learned more working in a group than they would have working alone, and expressed a preference for working in a group if they had to do the class over again. This is consistent with other research on small groups in which it was reported that students like working in small groups even when their achievement does not increase (Natasi \& Clements, 1991; Palinscar \& Brown, 1989).

Students who worked alone reported significantly more use of supplemental materials to complete the case preparation chart. This finding supports the results of Klein and Doran (1999) who reported that college students who worked alone to learn accounting from a computer simulation accessed supplemental materials more than did those who worked in small groups. Since students in the current study did not have the opportunity to discuss the cases with their peers, their only means of gaining new perspectives on the case was to access relevant reading material or class notes. Given the large amount of new material covered in the class before the case analyses began, it is possible that students were unsure of what content related to the case problem or exactly how to use the available information.

The combination of time on task and use of materials presents an interesting portrait of student behavior among those who worked alone. These students reported dissatisfaction with the time available to complete the case chart, yet some of those who worked alone voluntarily turned in their cases with time remaining. Sev- 
eral explanations are possible: they did not perceive that the text or their notes would be of any help, or they simply did not know what material to access, or they were uncertain how to apply factual information to the resolution of the problem at hand.

Although students in both instructional methods were dissatisfied with the amount of time available to complete the case preparation charts, those who worked in groups were significantly less satisfied. For the group discussion to be effective and enhance individual learning, sufficient time must exist for individual preparation, a well-developed discussion, and the opportunity for all individuals to assess the input of their peers and then apply it to their own case analyses.

Students who worked alone were less likely than those who worked in groups to report that they would choose to work alone again if they had to do the class over. They were also less likely to report that they generally prefer to work alone on problem solving. Students may perceive groups as critical to performance because of the emphasis placed on teams in companies that recruit them and by professors in their college classes. Cross-functional teams are widely used in the workplace and students learn about this in their courses. (Aranda, Aranda, \& Conlon, 1998; Carter \& Narasimhan, 1996; Cavalier et al., 1995; Williams, Giunipero, \& Henthorne, 1994). Another possibility is that students may perceive the workload to be lessened when they work in groups during class. In this study, the groups were never required to meet outside of class time so some of the typical complaints about group work were averted.

\section{IMPLICATIONS}

The results of the current study provide some implications for instructors and designers who plan to implement case-based learning environments. Findings suggest that the use of discussion groups in case-based classes can be an effective and motivating method of instruction if students are prepared and time is available for both individual preparation and group discussion. The prevalent use of teams in many com- panies and in many industries puts pressure on higher education to graduate students with strong team skills as well as analytical and problem-solving skills. The case method allows students to build the necessary body of knowledge for their chosen profession while improving analytical and problem-solving abilities in a team environment (Carlson \& Schodt, 1995; Doriswami \& Towl, 1963; Erskine et al., 1998; Gragg, 1954; Lawrence, 1953; Levin, 1995; Matejka \& Cosse, 1981; McNair \& Hersum, 1954; Tillman, 1995). Students also have the opportunity to practice applying acquired knowledge to real situations faced by decision makers.

There were three limitations in the current research study. First, time was limited to a 75min class period. This put a cap on time available, which may have influenced the results, but it was a realistic limit because $75 \mathrm{~min}$ is a standard class period. Second, students were in the early stages of learning the case-analysis process and these two cases were the first two cases they analyzed without instructor direction. Finally, intact classes (not participants) were randomly assigned to treatments in the current study. While there was no significant difference in the GPAs of students in each class, their in-class experience prior to data collection may have influenced results.

Future research should focus on the steps in the case analysis process to identify if and when group discussions make a difference in performance in a way that affects the final outcome. Research should also focus on identifying ways to ensure that individuals prepare before undertaking group work. Because group work is time consuming, it would be advantageous to identify clearly just where in the problem-solving process groups should focus their efforts. Is it problem identification, or quantitative analysis, or alternative generation, or some combination? Both instructors and managers must be concerned with efficient and effective use of time. If individual preparation is critical to effective group performance then instructors and managers must find ways to ensure that individuals come to group meetings prepared.

Another area of concern is the structure of the groups themselves. Much has been written about different types of groups, but there is little 
empirical research linking these types of learning structures to the case method. Would students perform better if the groups were highly structured and each group member had a specific role to play? Would they perform better if the students were first taught to function as a self-directed team? Each approach to managing groups in the classroom has implications for the instructor's and the student's allocation of time and resources.

Research should also be conducted on the assessment measures used in case classes. Part of the difficulty in comparing group and individual performance stems from the difficulty in developing a consistent means of grading casewriting assignments. Further research may reveal more effective approaches to both designing and grading case-writing assignments. Research on the development of casescoring rubrics may lead to better understanding of differences in how individuals and groups approach problem solving. Continued research on how group discussions influence performance in a case-based environment might provide information that would help improve the case teaching process.

Anna E. Flynn is Vice President and NAPM Associate Professor with the National Association of Purchasing Management.

James D. Klein is Professor at Arizona State

University and Editor of the Development section of ETR\&D. He may be reached at james.klein@asu.edu.

\section{REFERENCES}

Albanese, M.A., \& Mitchell, S. (1993). Problem-based learning: A review of literature on its outcomes and implementation issue. Academic Medicine, 68(1), 5281.

Aranda, E.K., Aranda, L., \& Conlon, K. (1998). Teams: Structure, process, culture and politics. Upper Saddle River, NJ: Prentice Hall.

Astin, A.W. (1992). What matters most in college: Four critical years revisited. San Francisco: Jossey-Bass.

Aulls, M.W. (1998). Contributions of classroom discourse to what content students learn during curric- ulum enactment. Journal of Educational Psychology, 90(1), 56-69.

Brookfield, S.D., \& Preskill, S. (1999), Discussion as a way of teaching. San Francisco: Jossey-Bass, Inc.

Bruffee, K.A. (1995). Sharing our toys: Cooperative learning versus collaborative learning. Change, 27(19), 12-18.

Carlson, J.A., \& Schodt, D.W. (1995). Beyond the lecture: Case teaching and the learning of economic theory. Journal of Economic Education, 26(1), 17-28.

Carter, J.R., \& Narasimhan, R. (1996). A comparison of North American and European future purchasing trends. International Journal of Purchasing and Materials Management, 32(2), 12-22.

Carter, K. (1989), Using cases to frame mentor-novice conversation about teaching. Theory into Practice, 27, 214-222.

Cavalier, J.C., Klein, J.D., \& Cavalier, F.J. (1995). Effects of cooperative learning on performance, attitude, and group behaviors in a technical team environment. Educational Technology Research and Development, 43(3), 61-71.

Christensen, C.R. (1987). Teaching and the case method. Boston: Harvard Business School.

Christensen, C.R., Garvin,, D.A., \& Sweet, A. (1991). Education for judgment: The artistry of discussion leadership. Boston: Harvard Business School Press.

Cliff, W.H., \& Wright, A.W. (1996). Directed case study method for teaching human anatomy and physiology. Advances in Physiology Education, 15(1), S19-S28.

Cooper, J.L., \& Mueck, R. (1992). Student involvement in learning. In A. Goodsell, M. Maher, \& V. Tinto (Eds.), Collaborative learning: A sourcebook for higher education. University Park, PA: National Center on Postsecondary Teaching, Learning, and Assessment.

Cooper, J.L., Robinson, P.R., \& McKinney, M. (1994). Cooperative learning in the classroom. In D.F. Halpern and Associates, Changing college classrooms: New teaching and learning strategies for an increasingly complex world. San Francisco: Jossey-Bass, 1994.

Cross, K.P., \& Steadman, M.H. 1996). Classroom research: Implementing the scholarship of teaching. San Francisco: Jossey-Bass Publishers.

Doriswami, M., \& Towl, A.R. (1963). ASCI Case Collection. AISA Publishing House.

Droge, C., \& Spreng, R. (1996). Enhancing involvement and skills with a student-led method of case analysis. Journal of Marketing Education, 18(3), 25-34.

Erskine, J.A., Leenders, M.R., \& Mauffette-Leenders, L.A. (1981). Teaching with cases (1st ed.). London, Ontario, Canada: Ivey Publishing, Richard Ivey School of Business, The University of Western Ontario.

Erskine, J.A., Leenders, M.R., \& Mauffette-Leenders, L.A. (1998). Teaching with cases (2nd ed.). London, Ontario, Canada: Ivey Publishing, Richard Ivey School of Business, The University of Western Ontario.

Ertmer, P.A., \& Quinn, J. (1999). The ID casebook: Case studies in instructional design. Upper Saddle River, 
NJ: Prentice-Hall, Inc.

Ertmer, P.A., \& Russell, J.D. (1995). Using case studies to enhance instructional design. Educational Technology, 35(4), 23-31.

Florio-Ruane, S., \& Clark, C.M. (1990). Using case studies to enrich field experiences. Teacher Education Quarterly, 17, 17.28.

Gallagher, S.A., \& Stepien, W.J. (1996). Content acquisition in problem-based learning: depth versus breadth in American Studies. Journal for the Education of the Gifted, 19(3), 257-275.

Gallagher, S.A., Stepien, W.J., \& Rosenthal, H. (1992). The effects of problem-based learning on problem solving. Gifted Child Quarterly, 36(4), 195-200.

Graf, D. (1991). A model for instructional design case materials. Educational Technology Research and Development. 39(2), 81-88.

Gragg, C.I. (1954). Because wisdom can't be told. In M.P. McNair (Ed.), The case method in the Harvard Business School (p. 6). New York: McGraw-Hill.

Greenwood, G.E., \& Parkey, F.W. (1989). Case studies for teacher decision-making. New York: Random House.

Griffith, P.L., \& Laframboise, K. (1997). The structures and patterns of case method talk: what our students taught us. Action in Teacher Education, 18(4), 10-22.

Haynes P.J., \& Helms, M.M. (1993). Increasing participation in case method courses. Journal of Management Education, 17(1), 114-117.

Herreid, C.F. (1994). Case studies in science education. Journal of College Science Teaching, 23, 221-229.

Horn, E.M., Collier, W.G., Oxford, J.A., Bond, C.F., Jr., \& Dansereau, D.F. (1998). Individual differences in dyadic cooperative learning. Journal of Educational Psychology, 90(1), 153-161.

Johnson, D.W., \& Johnson, R.T. (1989). Cooperation and competition: Theory and research. Edina, MN: Interaction Book Company.

Johnson, D.W., Maruyama, G., Johnson, R.T., Nelson, D., \& Skon, L. (1981). Effect of cooperative, competitive and individualistic goal structures in achievement: A meta analysis. Psychological Bulletin, 89, 47-62.

King, A., Staffieri, A., \& Adelgais, A. (1998). Mutual peer tutoring: Effects of structuring tutorial interaction to scaffold peer learning. Journal of Educational Psychology, 90(1), 134-152.

Kinzie, M B., Hrabe, M.E., \& Larsen, V.A. (1998). An instructional design case event: Exploring issues in professional practice. Educational Technology Research and Development, 46(1), 53-71.

Klein, J.D., \& Doran, M.S. (1999). Implementing individual and small group learning structures with a computer simulation. Educational Technology Research and Development, 47(1), 97-109.

Kleinfeld, J. (1990). The special virtues of case method in preparing teachers for minority schools. Teacher Education Quarterly, 17, 43-52.

Knechel, W.R., (1992). Using the case method in accounting instruction. Issues in Accounting Educa- tion, 7(2), 205-217.

Kowalski,T.J., Weaver, R.A., \& Henson, K.T. (1990). Case studies on teaching. New York: Longman.

Lawrence, P.R. (1953). The preparation of case material. In K.P. Andrews (Ed.), The case method of teaching human relations and administration (p. 215) Cambridge, MA: Harvard University Press.

Leenders, M.R., Fearon, H.E., \& Flynn, A.E. (1997). Purchasing and supply management. Chicago: Richard D. Irwin.

Levin, B.B. (1995). Using the case method in teacher education: The role of discussion and experience in teachers thinking about cases. Teaching and Teacher Education, 11(1), 63-79.

Matejka, J.K., \& Cosse, T.J. (1981). The business case method: An introduction. Richmond: Robert F. Dame.

Mauffette-Leenders, L.A., Erskine, J.A., \& Leenders, M.R. (1997). Learning with cases. London, Ontario, Canada: Case and Publication Services, Richard Ivey School of Business, The University of Western Ontario.

McNair, M.P., \& Hersum, A.C. (1954). The case method at the Harvard Business School. New York: McGrawHill Book Company, Inc.

Merseth, K.K. (1991) The early history of case-based instruction. Journal of Teacher Education, 42(4), 243249.

Natasi, R.K., \& Clements, D.H. (1991). Research on cooperative learning: Implications for practice. Psychology Review.

Nii, L.J., \& Chin, A. (1996). Comparative trial of problem-based learning versus didactic lectures on clerkship performance. American Journal of Pharmaceutical Education, 80, 162-164.

Palinscar, A.S., \& Brown, A.L. (1989). Classroom dialogues and promoting self-regulated comprehension. In J. Brophy (Ed.), Advances in research on teaching, 1, 35-71. New York: JAI Press.

Richardson, V. (1991). The use of cases in considering methods for motivating students. Paper presented at the annual meeting of the American Educational Research Association, Washington, D.C.

Shulman, J. (Ed.). (1992), Case method in teacher education. New York: Teachers College Press.

Siciliano, J., \& McAleer, G.M. (1997). Increasing student participation in case discussions: Using the MICA method in strategic management courses. Journal of Management Education, 21(2), 209-220.

Slavin, R.E. (1983). When does cooperative learning increase student achievement? Psychological Bulletin, 94, 429-445.

Slavin, R.E. (1989). Cooperative learning and student achievement. In R.E. Slavin (Ed.), School and classroom organization (pp. 129-156). Hillsdale, NJ: Erlbaum.

Slavin, R.E. (1990). Cooperative learning: Theory, research, and practice. Englewood Cliffs, NJ: Prentice Hall.

Specht, L.B., \& Sandlin, P.K. (1991, June). The differential effects of experiential learning activities and traditional lecture classes in accounting. Simulation and 
Gaming, 22, 196-210.

Stolovitch, H.D., \& Yapi, A. (1997). Use of case study method to increase near and far transfer of learning. Performance Improvement Quarterly, 10(2), 64-82.

Tillman, B.A. (1995). Reflections on case method teaching. Action in Teacher Education 17(1), 1-8.

Welty, W. (1989, July/August). Discussion method teaching: How to make it work. Change, 41-49.

White, H.B., III. (1996). Addressing content in problem-based courses: The learning issue matrix. Biochemical Education, 24(1), 41-45.

Wilkerson, L., \& Feletti, G. (1989). Problem-based learning: One approach to increasing student participation. In A.F. Lucas (Ed.), The department chairperson's role in enhancing college teaching. New Directions for Teaching and Learning, 37, 51-60.

Wilkinson, J., \& Dubrow, H. (1991). Encouraging independent thinking. In C.R. Christensen, D.A. Garvin, \& A. Sweet (Eds.), Education for judgment (pp. 249261). Boston, MA: Harvard Business School Press.

Williams, A.J., Giunipero, L.C., \& Henthorne, T.L. (1994). The cross-functional imperative: The case of marketing and purchasing. International Journal of Purchasing and Materials Management, 30(3), 29-33. 